\title{
Assessment of the Biogas Yield of White Mustard (Sinapis alba) Cultivated as Intercrops
}

\author{
Alicja Słomka ${ }^{1 *}$, Katarzyna Wójcik Oliveira' \\ ${ }^{1}$ Lublin University of Technology, Faculty of Environmental Engineering, ul. Nadbystrzycka 40B, \\ 20-618 Lublin, Poland \\ * Corresponding author's e-mail: ala.slomka08@gmail.com
}

\begin{abstract}
Popularization of intercrops in agriculture, resulting in an increased sequestration of carbon dioxide may bring additional benefits, becoming a source of biomass constituting a feedstock for biogas production. The residue formed in the course of biogas production, i.e. digestate, is also an alternative or a valuable supplement for mineral fertilizers necessary to maintain the proper condition of the agricultural soil. Therefore, the application of substrates from the intecrop biomass enables to improve the quality of soil, without sacrificing the main crop, by preventing the leaching of nutrients; it also reduces the risk of plant diseases, has a significant influence on diversification of energy sources, and contributes to solving the issue of excessive greenhouse gases emission. The aim of the work was to investigate the biogas and methanogenic potential of white mustard (Sinapis alba) and estimate the biogas efficiency of its biomass (the above-ground part) per hectare of arable land. The studies were conducted on the plants cultivated on experimental plots located in Emilianów and Wierzbica (Lubelskie Voivoideship). The cultivation of plants was conducted simultaneously, as stubble crop. The studies indicated a significant quantitative and qualitative differentiation of plant biomass collected from particular plots. The $\mathrm{C}: \mathrm{N}$ ratio, which constitutes the basic factors governing the correct course of methane fermentation, in the case of the shoot biomass of the considered plants, ranged from 13.5:1 to 19.9:1, depending on the location. The biomass efficiency of mustard biomass ranged from $0.6 \mathrm{t} \mathrm{d} . \mathrm{m}$. ha ${ }^{-1}$ to $0.8 \mathrm{t} \mathrm{d}$.m. ha ${ }^{-1}$, whereas its biogas potential amounted to $350-440 \mathrm{~m}^{3} \mathrm{t}^{-1} \mathrm{~d}$.m. Therefore, one hectare of intercrop mustard yields $264-280 \mathrm{~m}^{3}$ of biogas and the produced digestate can be recirculated to the soil, increasing the amount of biogenic substances and enriching it with humic substances.
\end{abstract}

Keywords: anaerobic fermentation, biogas, catch crops, methanogenic potential

\section{INTRODUCTION}

As the conventional sources energy become depleted and the energy demand increase, the actions aimed to increase the availability of renewable energy by using the biogas obtained through anaerobic fermentation, are taken. The production of renewable energy from biogas is a beneficial technology, contributing, i.a. to mitigation of greenhouse gases emission, inactivation of pathogens and reuse of nutrients, as well as regional/local economic development (Fröschle et al., 2015; Molinuevo-Salces et al., 2014).

Methane is one of the greenhouse gases (GHGs) originating mainly from the anthropogenic activity, including waste management, agriculture, as well as natural sources, such as swamp areas (Pawłowska et al. 2011), SzafranekNakonieczna et al. 2018).

However, in the anaerobic digestion process, methane is produced on purpose. The organic compounds contained in plant biomass, organic waste or wastewater are converted into biogas and digestate which enables their use as green energy and in agriculture, through the application of nutrients (Lalak et al., 2016; Oleszek and Matyka, 2017; Win et al., 2018; Kasprzycka and Kuna, 2018).

Raw biogas produced through fermentation contains $50-70 \%(\mathrm{v} / \mathrm{v})$ of methane, depending on the feedstock, the remaining part is mainly $30-45 \%(\mathrm{v} / \mathrm{v})$ of carbon dioxide, and 
small amounts of water $\left(\mathrm{H}_{2} \mathrm{O}\right)$, oxygen $\left(\mathrm{O}_{2}\right)$, hydrogen sulfide $\left(\mathrm{H}_{2} \mathrm{~S}\right)$, ammonia $\left(\mathrm{NH}_{3}\right)$ and other trace gases (Biomethane plants in Europe in 2015 (EBA Statistical Report, 2016)). Following the removal of carbon dioxide, the energy content in biogas increases the energy content, which is proportional to methane concentration (Petersson and Wellinger, 2009).

The application of intercrops as the biomass cultivated after the main harvest enables to improve the phytosanitary conditions of soil by preventing the leaching of nutrients and production of agricultural biogas, without a loss in the main crop, i.e. interfering with food production (Molinuevo-Salcesi et al., 2013). This significantly contributes to the mitigation of climatic changes by limiting the emission of greenhouse gases.

The intercrop biomass gives a multitude of possibilities. It can be used for two purposes: enriching soil with nitrogen through binding this element in the plant, and as fuel, following biochemical conversion, i.e. conversion of biogas in the methane fermentation process (MolinuevoSalcesi et al., 2014).

The net energy efficiency per hectare, which depends not only on the methane efficiency, but also on the biomass efficiency per hectare $\left(\mathrm{m}^{3} \mathrm{CH}_{4} / \mathrm{ha}\right)$, is a key parameter for the application of intercrops as substrates in methane fermentation (Seppäla M. et al., 2008).

Plant biomass, due to high content of lignocellulosic substances, comprising mainly cellulose, hemicellulose, and lignin, requires pretreatment in order to improve susceptibility to biodegradation (Dehkhoda 2008)

The aim of the work was to investigate the biogas and methanogenic potential of white mustard (Sinapis alba) and estimation of the biogas efficiency of its biomass (above-ground part) per hectare of agricultural land.

\section{MATERIALS AND METHODS}

\section{Catch crops biomass}

The biomass of white mustard (Sinapis alba) was used as the research material. This species was cultivated on experimental plots in two locations, i.e. Emilianów and Wierzbica villages in the Lublin Province. White mustard was sown in Emilianów on $15^{\text {th }}$ August on a field with the arable area of 2.4 ha, whereas in Wierzbica, it was sown on $16^{\text {th }}$ July on arable area of 0,5 ha. Biomass was collected on $19-20^{\text {th }}$ October, which is shown in Table 1. Wheat is the main crop cultivated in Emilianów, whereas in Wierzbica, where ecological cultivation system was employed, raspberry is dominant.

In experimental plots, fresh plant biomass was cut $5 \mathrm{~cm}$ above the ground over the area of $0.5 \mathrm{~m}^{2}$ (Photo 1) and promptly transported to the laboratory of Lublin University of Technology (LUT). Wet intercrop biomass from each plot was weighed in two repetitions using WPT2 and WPTS 2100 scales, then placed on white paper in LUT laboratory in order to dry it at room temperature and achieve air dry mass.

Dry biomass was weighed again, and its above-ground part was ground mechanically using electric mills.

\section{Analytical methods}

Dry biomass of white mustard from particular experimental plots following mechanical grinding was subjected to gravimetric determinations. Moisture and dry mass content was determined with the loss-on-drying method (PN-EN 15934:2013-02). The dry organic mass content and ash content (inorganic substance content) were determined on the basis of loss-on-ignition method in muffle furnace at $550^{\circ} \mathrm{C}$.

Total Kjeldahl Nitrogen (TKN) analysis of dry ground biomass was performed using FOSS TECATOR 8200 Kjeltec apparatus. The samples

Table 1. Characteristics of experimental plots

\begin{tabular}{|c|c|l|c|c|}
\hline Location & Pre-crop & \multicolumn{1}{|c|}{ Intercrop } & Date of sowing & $\begin{array}{c}\text { Date of collection } \\
\text { (above-ground part) }\end{array}$ \\
\hline EMILIANÓW & Wheat & $\begin{array}{l}\text { White mustard (Sinapis alba); } \\
\text { Blue tansy (Phacelia tanacetifolia); } \\
\text { Radish (Raphanus sativus) }\end{array}$ & 15.08 .18 & 19.10 .18 \\
\hline WIERZBICA & $\begin{array}{l}\text { Raspberry } \\
\text { plantation }\end{array}$ & $\begin{array}{l}\text { White mustard (Sinapis alba); } \\
\text { Blue tansy (Phacelia tanacetifolia) }\end{array}$ & 16.07 .18 & 20.10 .18 \\
\hline
\end{tabular}


a)

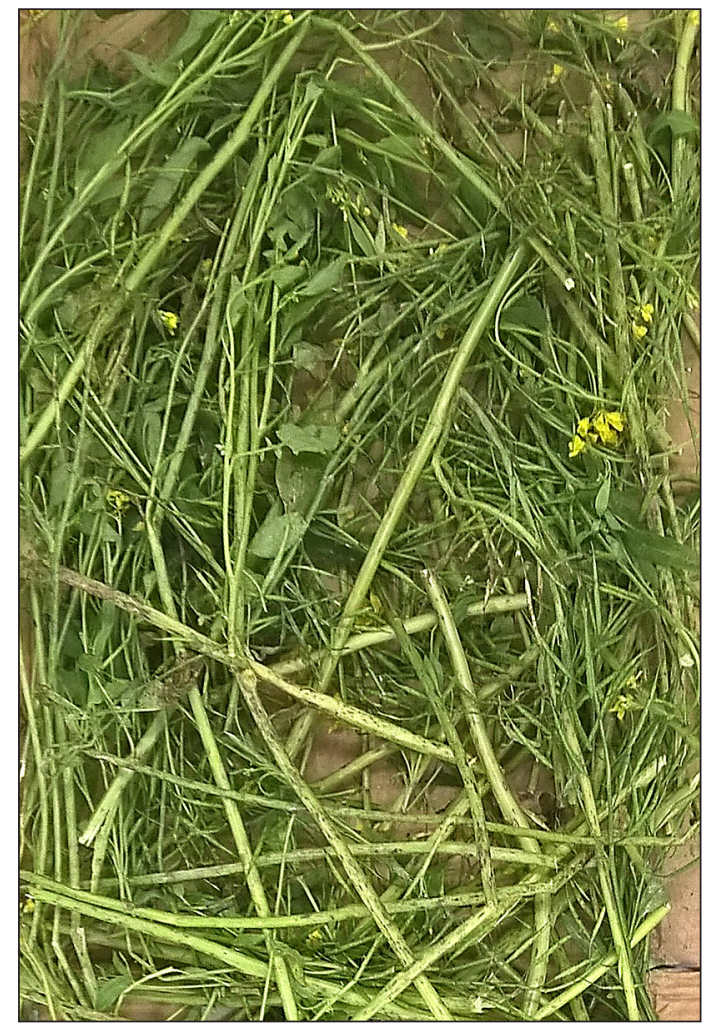

Wierzbica b)

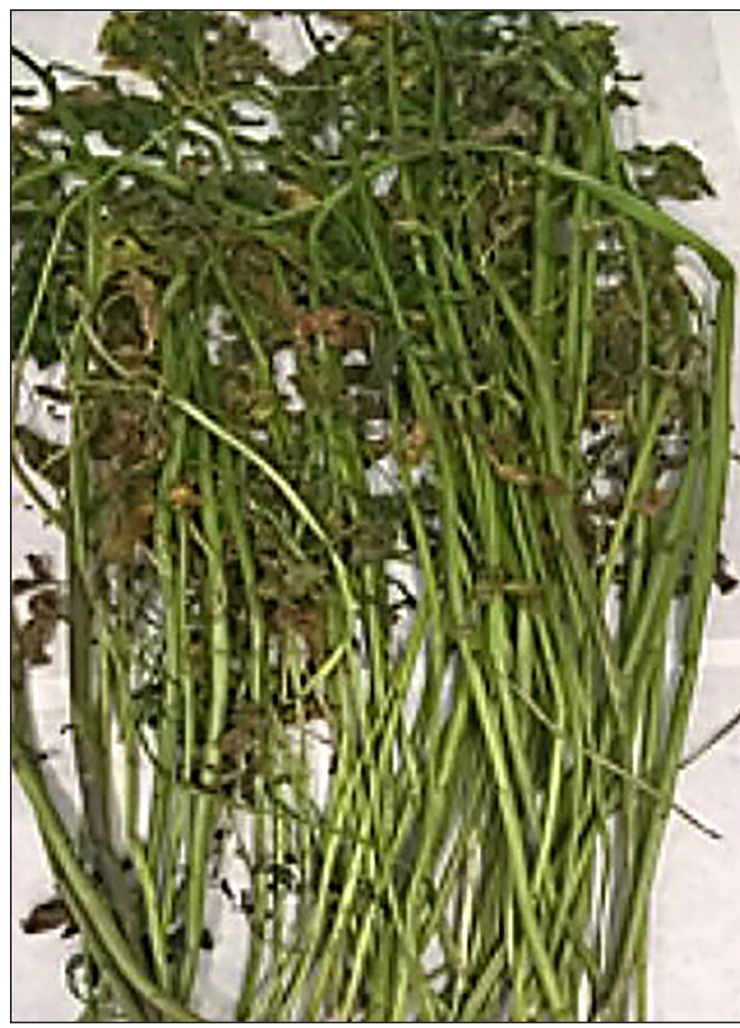

Emilianów

Figure 1. White mustard biomass (above-ground parts) harvested from different locations

with the mass of approximately $1.5 \mathrm{~g}$ were subjected to mineralization in the mineralizing block of the apparatus at a temperature of $420^{\circ} \mathrm{C}$ in accordance with the guidelines found in the application note no. 3503. After cooling, the mineralisate was placed in a distillation unit. Determination of nitrogen was performed by titrating $0.1 \mathrm{~N}$ distillate with a hydrochloric acid solution. Simultaneously, a blank test was performed.

Total organic carbon (TOC) content of dry mass of plants following mechanical grinding was determined using TOC-5050A automatic analyzer by Schimadzu. The biomass parameters including the content of dry organic mass, carbon, and total nitrogen, were determined twice from each plot.

\section{Biomethanogenic potential test}

The investigations pertaining to the biogas and methanogenic potential of white mustard (Sinapis alba) were performed in batch system using the BioReactor Simulator (Bioprocess Control, Sweden). BRS automatic testing system comprised two units: BRS-A and BRS-B (Photo 2), where: BRS-A consists of 6 reactors with the capacity of
$2 \mathrm{~L}$ each, whereas BRS-B is used to measure the volume of gas, and the integrated data acquisition system used to collect data and display results. The inoculum adaptation lasted for 31 days and was conducted under thermophilic conditions (at a temperature of $55 \pm 1^{\circ} \mathrm{C}$ ). The substrates were mixed with a slow stirrer in the discontinuous system (10 minutes of mixing at a speed of 20 rotations per minute and 50 minutes break).

The reactors were fed with $800 \mathrm{ml}$ of digestate from a biogas plant in Siedliszczki (Lublin Province, Eastern Poland). Substrate loading amounted to $10 \mathrm{~g}$ of ground dry biomass of white mustard for each bioreactor, the inoculums to substrate ratio was determined at 8:1 (based on dry biomass). Anaerobic fermentation was performed in four reactors: R1 and R6 for Wierzbica as well as R2 and R5 for Emilianów.

\section{Soil}

The soil samples were collected from plots in the villages of Wierzbica and Emilianów to a depth of $0-25 \mathrm{~cm}$. The samples were analyzed for the determination of moisture content, dry organic matter content, soil $\mathrm{pH}$, soil bulk density 


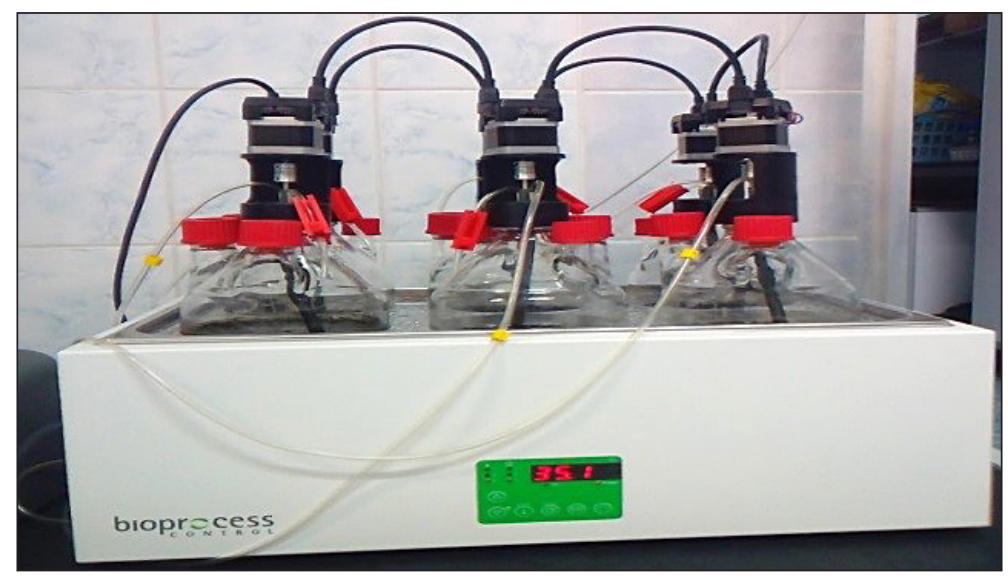

Figure 2. Set up for biogas potential determination.

Bioreactor Simulator (Bioprocess Control, Sweden)

and soil grain composition. The humidity and dry matter content were determined by using the losson-drying method at the temperature of $105^{\circ} \mathrm{C}$ to constant weight (PN-EN 15934:2013-02). Dry organic matter content and ash content (content of inorganic substances) were determined on the basis of the mass loss-on-ignitionat the temperature of $550^{\circ} \mathrm{C}$. The dried samples were calcined in a muffle furnace to constant weight. The $\mathrm{pH}$ was measured using the potentiometric method in an aqueous suspension, which was obtained by mixing the soil sample with distilled water in the ratio of 1:5 (v:v). An Elmetron CP-401 pH meter with a calomel electrode (combined) was used for the measurement. The bulk density of soil was determined with the Kopecky cylinder method. The hydrometric method was used with the use of a Prószyński hydrometer, in which $40 \mathrm{~g}$ of air-dried soil sample (sieve with mesh size of $2.0 \mathrm{~mm}$ ) was used for each field, with the temperature in each cylinder equal to $22^{\circ} \mathrm{C}$

The measurement was determined in two sieved soil samples from each field $(2.0 \mathrm{~mm}$ mesh size).

\section{RESULTS}

\section{Soil characterization}

The soil characteristics before sowing are presented in Table 2. The average moisture content in the tested samples was $5.69 \%$ for Wierzbica and $5.06 \%$ for Emilianów, respectively. The texture of the soil has an absolute influence on the low moisture content and the storage capacity. In the case of the tested samples, the fractions and grain size composition of the soils were determined, which indicates a light loamy sand type soil for both locations. The $\mathrm{pH}$ value was 7.72 for Wierzbica, i.e. alkaline, while for Emilianow, the $\mathrm{pH}$ of soil was slightly acidic -6.48 . Most plants grow well in the $\mathrm{pH}$ range of 6-7, due to optimal nutrient availability (Roy et al., 2006).

\section{Biomass}

The physicochemical analysis of white mustard biomass is presented in Table 3. The yield of dry white mustard biomass in tonnes per hectare varied quantitatively between locations, for Wierzbica it was $0.8 \mathrm{td}$ d.m. ha ${ }^{-1}$, and for Emilianów 0.6 $\mathrm{t}$ d.m., respectively ha $\mathrm{a}^{-1}$. Sowing time (Table 1 ) at both sites was different, which could have had a significant impact on the biomass performance

Table 2. Physicochemical parameters of soil

\begin{tabular}{|l|c|c|c|}
\hline \multicolumn{1}{|c|}{ Parameters } & Units & Wierzbica & Emilianów \\
\hline moisture \% d.m. & $\%$ & $5.69 \pm 0.01$ & $5.06 \pm 0.05$ \\
\hline $\mathrm{pH}$ & & $7.71 \pm 0.03$ & $6.48 \pm 0.08$ \\
\hline$\gamma$ & $\mathrm{g} / 100 \mathrm{~cm}^{3}$ & $0.94 \pm 0.00$ & $0.90 \pm 0.03$ \\
\hline soil fraction & $\%$ & $53-45$ & $31-67$ \\
\hline $\begin{array}{l}\text { soil granulometric } \\
\text { composition }\end{array}$ & $\%$ & $40-10$ & $45-15$ \\
\hline
\end{tabular}

Table 3. Physico-chemical analysis of the research material

\begin{tabular}{|c|c|c|c|}
\hline Parameters & Units & Wierzbica & Emilianów \\
\hline \multirow[t]{2}{*}{ Dry organic mass } & \%d.m. & $90.32 \pm 0.26$ & $86.73 \pm 0.29$ \\
\hline & t d.m. ha ${ }^{-1}$ & 0.8 & 0.6 \\
\hline TKN & $\mathrm{gkg}^{-1}$ & $2.08 \pm 0.02$ & $2.60 \pm 0.01$ \\
\hline TOC & $\mathrm{gkg}^{-1}$ & $41.58 \pm 0.05$ & $40.66 \pm 0.80$ \\
\hline $\mathrm{C} / \mathrm{N}$ & & 19.9:1 & $15.6: 1$ \\
\hline
\end{tabular}




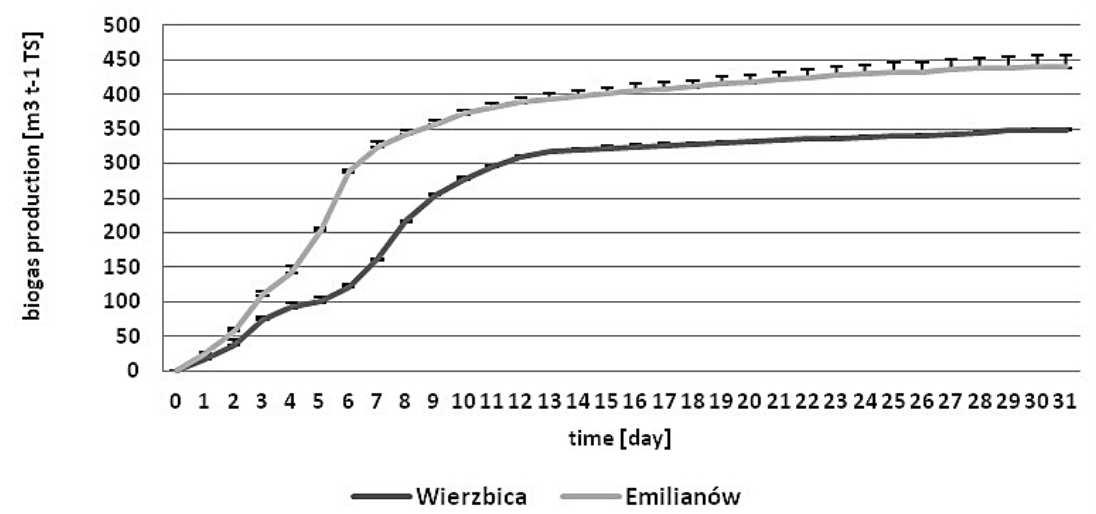

Figure 3. Production of biogas in $\mathrm{m}^{3} \mathrm{t}^{-1} \mathrm{TS}$ for: Wierzbica and Emilianów.

between sites. The growing period for the crops located in Wierzbica was longer, which translated into a higher amount of biomass obtained.

The concentration of macronutrients in the white mustard substrate depending on the location, i.e. the organic carbon and general nitrogen were in the range of 40.66-41.58 and 2.6-2.08, respectively, where the $\mathrm{C} / \mathrm{N}$ ratio was set at 15.5:1 for Emilianów and 19.9:1 for Wierzbica. The carbon-nitrogen ratio is an important parameter in methane fermentation, and the optimal range of these elements should be between 20 and 35 (Mao et al., 2015).

\section{Biogas potential}

Analysis of the amount of biogas yield for Wierzbica and Emilianów was shown in the curve in Figure 1. This curve is formed by daily summation of the amount of biogas, and the maximum value is the sum of the amount of biogas from each day. The curve shown is the averaged total amount of biogas from reactor R1 and R6 for Wierzbica as well as R2 and R5 for Emilianów.

Highest total amount of biogas produced for dry biomass in fermentation was observed at the end of the experiment ( $31^{\text {th }}$ day) for Emilianów at $440 \mathrm{~m}^{3} \mathrm{t}^{-1}$, slightly less for Wierzbica at $350 \mathrm{~m}^{3} \mathrm{t}^{-1}$. The yield of mustard biomass ranged from $0.6 \mathrm{t} \mathrm{d} . \mathrm{m}$. ha ${ }^{-1}$ do $0.8 \mathrm{t} \mathrm{d} . \mathrm{m}$. ha ${ }^{-1}$; thus, it is possible to obtain from 264 to $280 \mathrm{~m}^{3}$ of biogas from a single hectare of intercrop biomass. It can be seen that the biogas yield for Emilanów is higher than for Wierzbica. The growing time of catch crop biomass may determine the contribution of cellulose, hemicellulose, ligin and other constituents in plant biomass. The presence of lignins is one of the disadvantages of lignocellulosic biomass used during fermentation, making the compounds contained in substrates resistant to chemical and biological degradation (Taherzadeh et al., 2007).

\section{CONCLUSIONS}

The use of white mustard as inter-crop biomass in methane fermentation seems to be a good direction as a potential source of renewable bioenergy. Using the substrate as an additive in biogas production can be profitable, because it does not interfere with the production of food and fodder plants. The use of intercrops as a substrate can even increase the efficiency of the soil nutrient management system, as a result of digestate introduced in the soil during fermentation.

Studies have shown a variation in biogas yield and quality per hectare of white mustard biomass collected from individual plots. Future research into the use of different intercrop biomass substrates in anaerobic fermentation can be the answer and provide a sustainable alternative to agricultural waste in biogas production.

\section{REFERENCES}

1. EBA Statistical Report, 2016. Biomethane plants in Europe in 2015

2. Dehkhoda A., 2008. Concentrating lignocellulosic hydrolysate by evaporation and its fermentation by repeated fed batch using flocculating Saccharomyces cerevisiae. Master thesis, Industrial Biotechnology Boras University and SEKAB E-Technology, Sweden.

3. Salces B.M.., Ahring B.K., Uellendahl H. 2013. Catch crops as an alternative biomass feedstock for biogas plants. Proceedings of the International Anaerobic Digestion Symposium on "Dry 
Fermentation, Substrate Treatment and Digestate Treatment" within the BioGasWorld 2013.

4. Molinuevo-Salces, R. Fernández-Varela, H. Uellendahl. 2014. Key factors influencing the potential of catch crops for methane production. Environ. Technol., 35, 1685-1694.

5. Petersson A., Wellinger A. 2009. Biogas upgrading technologies-developments and innovations, IEA Bioenergy

6. Seppäla M., Paavola T., Lehtomaki A., Pakarien, O., Rintala, J. 2008. Biogas from energy crops-optimal pre-treatments and storage, co-digestion and energy balance in boreal conditions. Water Science and Technology, 58(9), 1857-1863.

7. Fröschle, B., Heiermann, M., Lebuhn, M., Messelhäusser, U., Plöchl, M.. 2015. Hygiene and sanitation in biogas plants. In: Guebitz, G.M., Bauer, A., Bochmann, G., Gronauer, A., Weiss, S. (Eds.), Biogas Science and Technology, Springer International Publishing, 151, 63-99.

8. Pawłowska, M., Rożej, A., Stępniewski, W. 2011. The effect of bed properties on methane removal in an aerated biofilter - model studies, Waste Manag., 31, 903-913.

9. Szafranek-Nakonieczna, A., Zheng, Y., Słowakiewicz, M., Pytlak, A., Polakowski, C., Kubaczyński, A., Bieganowski, A., Banach, A., Wolińska, A., Stepniewska, Z. 2018. Methanogenic potential of lignite in Poland., Int. J. Coal Geol., 196, 201-210.

10. Lalak, J., Kasprzycka, A., Martyniak, D., Tys, J. 2016. Effect of biological pretreatment of Agropyron elongatum 'BAMAR' on biogas production by anaerobic digestion. Bioresour. Technol., 200, 194-200.

11. Oleszek, M., Matyka, M. 2017. Nitrogen fertilization level and cutting affected lignocellulosic crops properties important for biogas production. Bioresources, 12, 8565-8580.

12. Kasprzycka, A., Kuna, J. 2018. Methodical aspects of biogas production in small-volumem bioreactors in laboratory investigations. Energies, 11, 1378. https://doi.org/10.3390/en11061378.

13. Mao C., Feng Y., Wang X., Ren G. 2015. Review on research achievements of biogas from anaerobic digestion. Renewable and Sustainable Energy Reviews, 45, 540-555.

14. Roy R.N., Finck A., Blair G.J., Tandon H.L.S. 2006. Plant nutrition for food security: a guide for integrated nutrient management. FAO Fertilizer and Plant Nutrition Bulletin. Rome: Food and Agriculture Organization of the United Nations., 368, Report No:16.

15. Taherzadeh M.J., Karimi K. 2007. Enzymatic-based hydrolysis processes for ethanol from lignocellulosic materials: a review. BioResources, 2, 707-738. 